\title{
Effect of Different Warm-up Strategies on Simulated Laparoscopy Performance: A Randomized Controlled Trial
}

\author{
Enrico Brönnimann, MD, ${ }^{1,}{ }^{*}$ Henry Hoffmann, MD, ${ }^{*}, 1$ Juliane Schäfer, PhD, ${ }^{*}{ }^{\dagger}$ Dieter Hahnloser, MD, ${ }^{\ddagger}$ \\ and Rachel Rosenthal, MD* \\ *Department of Visceral Surgery, University Hospital Basel, Basel, Switzerland; †Basel Institute for Clinical \\ Epidemiology and Biostatistics, University Hospital Basel, Basel, Switzerland; and \#Department of Visceral \\ Surgery, Lausanne University Hospital, Lausanne, Switzerland
}

OBJECTIVE: The objective of this trial was to assess which type of warm-up has the highest effect on virtual reality (VR) laparoscopy performance. The following warm-up strategies were applied: a hands-on exercise (group 1), a cognitive exercise (group 2), and no warm-up (control, group 3).

DESIGN: This is a 3-arm randomized controlled trial.

SETTING: The trial was conducted at the department of surgery of the University Hospital Basel in Switzerland.

PARTICIPANTS: A total of 94 participants, all laypersons without any surgical or VR experience, completed the study.

RESULTS: A total of 96 participants were randomized, 31 to group 1, 31 to group 2, and 32 to group 3 . There were 2 postrandomization exclusions. In the multivariate analysis, we found no evidence that the intervention had an effect on VR performance as represented by 6 calculated subscores of accuracy, time, and path length for (1) camera manipulation and (2) hand-eye coordination combined with 2-handed maneuvers ( $\mathrm{p}=0.795$ ). Neither the comparison of the average of the intervention groups (groups 1 and 2) vs control (group 3) nor the pairwise comparisons revealed any significant differences in VR performance, neither multivariate nor univariate. VR performance improved with increasing performance score in the cognitive exercise warm-up (iPad 3D puzzle) for accuracy, time, and path length in the camera navigation task.

Grant funding: This research was supported by the Swiss National Science Foundation, Switzerland (Grant no. 32003B-120722).

Correspondence: Inquiries to Henry Hoffmann, MD, Department of Surgery, University Hospital Basel, Spitalstrasse 21, 4031 Basel, Switzerland; e-mail: henry. hoffmann@usb.ch

${ }^{1}$ Equal contribution as first author.
CONCLUSIONS: We were unable to show an effect of the 2 tested warm-up strategies on VR performance in laypersons. We are currently designing a follow-up study including surgeons rather than laypersons with a longer warm-up exercise, which is more closely related to the final task. ( J Surg 72:96-103. @ 2014 Association of Program Directors in Surgery. Published by Elsevier Inc. All rights reserved.)

KEY WORDS: warm-up, laparoscopy, surgical outcome improvement, virtual reality

COMPETENCIES: Medical Knowledge, Practice-Based Learning and Improvement, Professionalism, Systems-Based Practice

\section{INTRODUCTION}

Preoperative warm-up strategies have recently emerged with the ultimate goal to minimize errors in surgery and improve patient outcomes. Similar to the field of sport, it is expected that a warm-up before surgical tasks, especially in laparoscopic surgery, shall raise the awareness for the planned psychomotor and cognitive tasks and thus support surgical performance and patient safety. This idea is progressively gaining acceptance: the global initiative ORReady, for example, aims to improve surgical outcomes by using check lists, time-outs, or warm-ups. ${ }^{1}$ The authors of the initiative believe that with such procedures more than 6 million patients worldwide could benefit from better outcomes.

However, only a few studies evaluated the benefit of a preoperative warm-up on surgical performance. Most studies investigated the effect of a "surgical" warm-up, where the warm-up task was related to the subsequent procedure. Warm-up was either conducted as "hands-on" exercise (e.g., pelvitrainers, virtual reality [VR] simulators, and robotic laparoscopy simulators) ${ }^{2-10}$ or "cognitive" exercise (e.g., mental rehearsal of steps of planned operation). ${ }^{11}$ Only few studies assessed "nonsurgical" warm-up strategies (unrelated 
to the subsequent procedure), consisting of hands-on exercises with computer games. ${ }^{2,12-14}$ Surgical performance was assessed as the outcome of interest, either during real operations $^{2,5-9,11}$ or in a simulated environment. ${ }^{3,4,10,12-14}$ Although 1 randomized controlled trial (RCT) suggested that there is no advantage of a warm-up, ${ }^{2}$ the other studies described a better performance after conducting a warm-up. This benefit was reflected by a gain in time, a decreased number of errors, a better economy of movement, an improved overall performance, and an enhanced cognitive awareness. ${ }^{3-14}$ However, some of the studies had limitations, such as the lack of a control group, ${ }^{3}$ a small number of participants, ${ }^{3,5-7,12}$ and a retrospective ${ }^{8}$ or prospective but nonrandomized design. ${ }^{3,12}$ Although a crossover design or a randomization of interventions instead of surgeons allows for intraindividual comparisons, a potential carry-over learning effect might influence the outcomes. ${ }^{5-7}$ Although some studies included a sample size statement, ${ }^{9-11}$ many of the studies did not include any rationale at all for the chosen sample size. A single study compared 2-in terms of setting-entirely different warm-up methods to each other. ${ }^{2}$ To the best of our knowledge, no study has so far evaluated the effect of a nonsurgical non-computer-based hands-on method such as table soccer and of a nonsurgical spatial skills-based cognitive method on VR performance.

The purpose of this 3-arm randomized controlled study was to assess the effect of a 5-minute warm-up with table soccer or with a tablet 3D puzzle, both relative to no warmup, on VR performance (primary research question). Additionally, we assessed whether experience in video games or in table soccer were independent predictors of VR performance and whether the tablet $3 \mathrm{D}$ puzzle score correlated with VR performance (secondary research questions).

\section{MATERIALS AND METHODS}

\section{Participants}

Our population of interest consisted of adult laypersons; individuals with surgical experience or laparoscopy VR simulator experience were excluded. To motivate laypersons for participation, we placed public placards illustrating the study aim from October 23 to 26, 2012, on our hospital ground.

\section{Participant Characteristics Questionnaire}

Participants completed a questionnaire asking characteristics such as age, sex, handedness, and experience in video games, with simulators and with table soccer.

\section{Study Design}

This study is a single-center 3-arm parallel group RCT (Fig.). We allocated the participants at random to the 3 groups: group 1: hands-on table soccer warm-up, group 2: cognitive tablet 3D puzzle warm-up, and group 3: no warm-up. We applied block randomization with block sizes of 6 , as generated using the online tool available at http://www.randomization.com (accessed 16.10.2012). The generated randomization list was then transmitted using serially numbered sealed opaque envelopes.

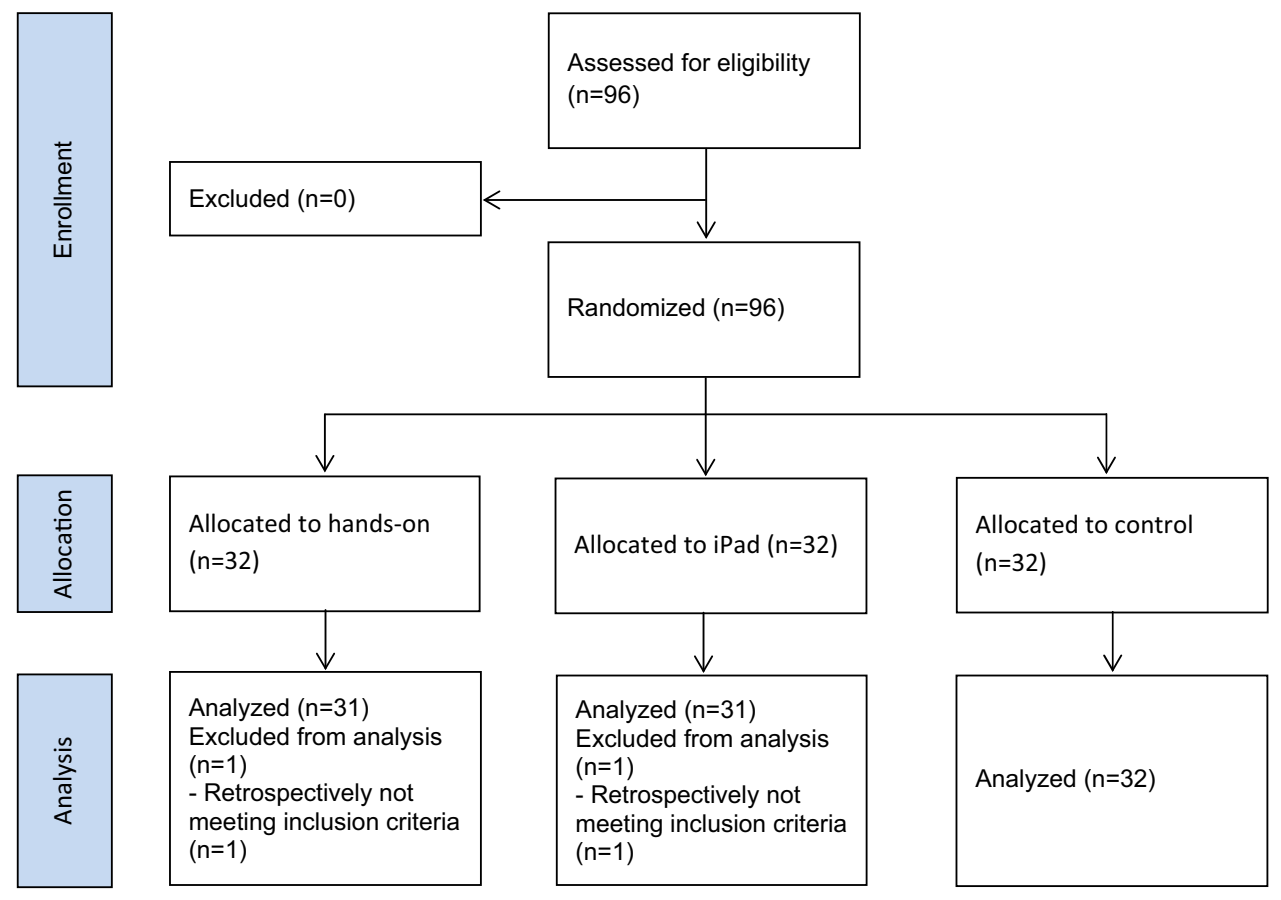

FIGURE. Study flow chart. 
For simulated laparoscopy performance assessment, participants accomplished 3 exercises of the basic tasks module on the laparoscopy simulator LAP Mentor (Simbionix, Cleveland, OH, USA) as outlined later.

\section{Warm-up Tasks}

For the hands-on warm-up, 2 participants played table soccer against each other for 5 minutes using a conventional table soccer game (Garlando Deluxe; Garlando SpA, Formigaro, Italy). As the opponents changed, performance in the table soccer game could not be measured in a standardized way. This is why we refrained from marking any scores after 5 minutes of play.

For the cognitive iPad (Apple Inc., USA) warm-up, participants played the tablet 3D puzzle "Fragmental 3D" (Aesthetic interactive, Grand Rapids, MI, USA) for 5 minutes. The game consists of arranging falling blocks on a 3-dimensional (3D) grid. These blocks can be moved and rotated in all directions to complete lines across the grid. Whenever a line is complete, it is cleared away and points are generated. The achieved points were marked after 5 minutes of play.

\section{Simulator Tasks}

We used 2 laparoscopy simulators with identical hardware and software to conduct the VR tasks. The hardware consisted of the LAP Mentor express hardware, running on a 17 -in widescreen (resolution $800 \times 600$ pixel). This software runs on a Windows XP operating system and simulates high-resolution graphics in real time. A choice of laparoscopic instruments is simulated, such as a camera and graspers with realistic instrument handles; all connected to the manipulation robots. The participants had to manage the following 3 tasks of the LAP Mentor basic tasks module: task 1 (camera manipulation), task 3 (hand-eye coordination), and task 6 (2-handed maneuvers). An instructor presented and explained each task in a standardized manner. Based on subject-matter knowledge, we grouped the outcomes recorded by the simulator into 3 dimensions: accuracy in percentage (\%) (i.e., maintaining the horizon in task 1 , touching the targets in task 3 , and collecting the balls in task 6), time to complete the task in seconds (evaluated for all 3 tasks), and path length of the camera (task 1) and of the right/left hand instrument (tasks 3 and 6) in centimeters.

\section{Standardized Score}

To represent simulated laparoscopy performance, we calculated a standardized score with mean of 100 and standard deviation (SD) of 15 for each of the 3 measured dimensions (accuracy, time, and path length, with the latter corresponding to the economy of movement) of task 1 and of tasks 3 and 6 taken together. The underlying algorithm reads as follows:
(1) Standardize all individual outcome measures of simulated laparoscopy performance to zero mean and unit variance to be able to compare the outcomes that are measured on different scales.

(2) Calculate the sum of measurements for tasks 3 and 6 grouped within the 3 dimensions (accuracy, time, and path length) to obtain composite scores defined according to a priori expert judgment.

(3) As each new composite score has zero mean but is reported on a different scale, standardize them again to unit variance; so the individual scores are expressed in standard deviation units.

(4) Reverse the scores for time and path length in task 1 and tasks 3 and 6 taken together so that higher scores correspond to better performance throughout.

(5) Finally, because we are more accustomed to positive numbers, standardize all scores to mean 100 and SD $15 . .^{15}$

\section{Statistical Analyses}

We first used 1-way analysis of variance (ANOVA) to assess if there is a difference in mean task 3 right hand instrument path length (outcome used for sample size calculation as outlined later) between the 3 study groups of hands-on table soccer warm-up, cognitive iPad warm-up, and control (no warm-up). We report estimates (with simultaneous 95\% CIs) of the difference for participants in the hands-on and iPad group, both relative to the control group. The Dunnett correction was used to adjust the CIs. ${ }^{16}$

With each participant scoring on 6 different subscores of simulated laparoscopy performance (accuracy, time, and path length for task 1 and tasks 3 and 6 taken together), we then used multivariate ANOVA to assess if there is a difference in mean simulated laparoscopy performance between the 3 study groups. For each subscore, we report estimates (with simultaneous 95\% CIs) of the difference for participants in the hands-on and iPad group, both relative to the control group (using the Dunnett multiple comparison adjustment ${ }^{16}$ ).

We performed 2 sensitivity analyses. First, we removed 3 participants with unusually high values of time or path length in tasks 3 and 6 (1 participant from the iPad group and 2 from the control group) to see whether our estimates were robust to outliers. Second, as the distribution of the reversed accuracy (100-accuracy [\%]), time (minute), and path length $(\mathrm{cm})$ was mildly skewed to the right, we used the square root and logarithmic transformation for the reversed accuracy and both time and path length, respectively, to see whether our estimates were robust to deviations from normality.

In an additional analysis, we used multivariate regression with the 6 subscores of simulated laparoscopy performance as the dependent variables; and as the independent variables, 
we included the study group (hands-on, iPad, or control), experience in table soccer, and experience in video games, both dichotomous with $\leq 5$ vs $>5$ hours experience.

For participants in the iPad group, we used scatter plots to explore the association between simulated laparoscopy performance and achieved tablet 3D puzzle score.

We used SAS version 9.2 (SAS Institute Inc., Cary, NC, USA) for our analyses; for graphics, we used $\mathrm{R}$ version 3.0.1 (R Foundation for Statistical Computing, Vienna, Austria) and the $\mathrm{R}$ add-on packages lattice version $0.20-24^{17}$ and latticeExtra version 0.6-26.

\section{Sample Size}

Since one of the warm-up strategies assessed in this study was a cognitive exercise consisting of a 3D spatial skills task, we chose to determine the sample size with respect to the right hand instrument path length in task 3 , which was a priori judged by our study team as most depending on spatial skills. In a previous investigation of individuals without surgical experience, we found a mean (SD) path length of $168 \mathrm{~cm}$ $(46 \mathrm{~cm})$ (submitted for publication). In an earlier study of surgical residents, ${ }^{18}$ a mean (SD) path length of $108 \mathrm{~cm}$ $(18 \mathrm{~cm})$ was found for the same task. We a priori defined as clinically relevant, if using the cognitive warm-up, participants without surgical experience improved over control half the difference between their performance and that of surgical residents, i.e., $30 \mathrm{~cm}$. Anticipating a more homogenous participant group than in our previous investigation of individuals without surgical experience, we assumed that the $\mathrm{SD}$ was $35 \mathrm{~cm}$. For the contrast between the iPad and control group, we determined the sample size required to achieve a power of $80 \%$ at 2-sided significance level $\alpha=$ 0.0167 (conservative Bonferroni correction to adjust for
3 pairwise comparisons) as 30 participants per group. The total sample size in this 3-arm trial was then inflated to 96 participants to account for anticipated dropouts.

\section{RESULTS}

\section{Participant Characteristics}

Of 96 randomized participants, 2 met the exclusion criteria. Both participants had experience in laparoscopy. Of the remaining, 31, 31, and 32 were randomized to the handson, iPad, and control group, respectively. Characteristics of included participants were balanced between the 3 groups (Table 1).

\section{VR Performance}

The median right hand instrument path length in task 3 (interquartile range) was 151 (117-174), 183 (137-208), and $158 \mathrm{~cm}$ (147-200) for participants in the hands-on, $\mathrm{iPad}$, and control group, respectively. The average subscores for the 3 dimensions within task 1 and within tasks 3 and 6 taken together showed only minimal differences between the study groups (Table 2).

\section{Effect of Nonsurgical Warm-up Strategies on VR Performance}

The estimated difference in task 3 right hand instrument path length (simultaneous $95 \% \mathrm{CI}$ ) was $16 \mathrm{~cm}(-44$ to 12$)$ for the hands-on group relative to the control group and for the iPad relative to the control group, it was $18 \mathrm{~cm}(-10$ to 47$)$.

The overall multivariate analysis showed that any differences in the 6 subscores of simulated laparoscopy

TABLE 1. Characteristics of Participants in the Hands-on, iPad, and Control Groups

\begin{tabular}{|c|c|c|c|}
\hline Characteristic & Hands-on $(n=31)$ & $\operatorname{iPad}(n=31)$ & Control $(n=32)$ \\
\hline Female gender, $n(\%)$ & 12 (39) & $9(29)$ & $14(44)$ \\
\hline Median age (IQR), years & $25(22-32)$ & 27 (21-34) & 27 (24-34) \\
\hline Right handed, $n(\%)$ & $28(90)$ & $31(100)$ & $30(94)$ \\
\hline \multicolumn{4}{|l|}{ Occupation/profession, n (\%) } \\
\hline Nurse & $1(3)$ & $1(3)$ & $3(9)$ \\
\hline Student & $20(65)$ & $18(58)$ & $18(56)$ \\
\hline Medical technician & $0(0)$ & $0(0)$ & $1(3)$ \\
\hline Doctor & $3(10)$ & $2(6)$ & $2(6)$ \\
\hline Other & 7 (23) & $10(32)$ & $8(25)$ \\
\hline \multicolumn{4}{|l|}{ Experience in video games, $n(\%)$} \\
\hline None & $9(29)$ & $5(16)$ & $6(19)$ \\
\hline$\leq 5$ hours & $3(10)$ & $5(16)$ & $2(6)$ \\
\hline$>5$ hours & $19(61)$ & $21(68)$ & $24(75)$ \\
\hline \multicolumn{4}{|l|}{ Experience in table soccer, $n(\%)$} \\
\hline None & $3(10)$ & $3(10)$ & $3(9)$ \\
\hline$\leq 5$ hours & $6(19)$ & $4(13)$ & $2(6)$ \\
\hline$>5$ hours & $22(71)$ & $24(77)$ & 27 (84) \\
\hline Experience with simulation, $n(\%)$ & $12(39)$ & $12(39)$ & $15(47)$ \\
\hline Median iPad score (IQR) & ריד & $230(140-288)$ & 1 \\
\hline
\end{tabular}

$I Q R$, interquartile range. 
TABLE 2. Average Subscores of Simulated Laparoscopy Performance for Participants in the Hands-on, iPad, and Control Groups

\begin{tabular}{|c|c|c|c|c|c|c|}
\hline \multirow[t]{2}{*}{$\overline{\text { Group }}$} & \multicolumn{3}{|c|}{ Task 1} & \multicolumn{3}{|c|}{ Tasks $3+6$} \\
\hline & Accuracy & Time & Path Length Camera & Accuracy & Time & Path Length Instruments \\
\hline $\begin{array}{l}\text { Hands-on }(n=31) \\
\text { iPad }(n=31) \\
\text { Control }(n=32)\end{array}$ & $\begin{array}{r}100.6 \\
98.6 \\
100.8\end{array}$ & $\begin{array}{r}101.3 \\
101.2 \\
97.6\end{array}$ & $\begin{array}{r}100.6 \\
98.6 \\
100.8\end{array}$ & $\begin{array}{r}100.6 \\
98.7 \\
100.6\end{array}$ & $\begin{array}{r}102.8 \\
98.9 \\
98.3\end{array}$ & $\begin{array}{r}104.2 \\
96.8 \\
99.0\end{array}$ \\
\hline
\end{tabular}

performance did not reliably depend on the study group ( $\mathrm{p}$ $=0.795$ ). The post hoc tests comparing (1) the average of the intervention groups (hands-on and iPad) with the control group and (2) each the hands-on and iPad group to the control group were not statistically significant (at a significance level of 5\%).

In addition, none of the 6 one-way ANOVAs was statistically significant, and neither the comparison of the average of the intervention groups with the control group nor the comparison of the hands-on and iPad groups with the control group were statistically significant for any of the 6 subscores.

The estimated differences (with simultaneous 95\% CIs) in simulated laparoscopy performance for participants in the hands-on and iPad groups, both relative to the control group, are shown in Table 3.

The results of the sensitivity analyses based on both the reduced data set and the transformed simulated laparoscopy performance outcomes were comparable to those from the main analysis (data not shown).

\section{Effect of Experience in Table Soccer and Video Games on VR Performance}

In the multivariate regression, any differences in the $6 \mathrm{VR}$ performance subscores did not reliably depend on the included predictors: the study group, experience in table soccer, and experience in video games $(\mathrm{p}=0.509)$. With the univariate results, the overall models for the subscores were not statistically significant nor were the predictors study group, experience in table soccer, or experience in video games (Table 4).

\section{Association Between VR Performance and iPad Score}

VR performance increased with increasing tablet 3D puzzle score for all dimensions in task 1 (camera navigation), whereas there was no apparent association between VR performance and tablet 3D puzzle score for tasks 3 (handeye coordination) and 6 (2-handed maneuvers) (data not shown).

\section{DISCUSSION}

In this 3-arm RCT, neither a 5-minute nonsurgical handson warm-up (table soccer) nor a 5-minute nonsurgical cognitive warm-up (tablet 3D puzzle) had an effect on VR performance. Although increasing tablet 3D puzzle scores were associated with improved performance in the camera navigation task (accuracy, time, and path length), this association was not observed in the hand-eye coordination and 2-handed maneuver tasks.

\section{Strengths and Limitations}

To our knowledge, this is the first study investigating the effect of 2 nonsurgical warm-up strategies on VR laparoscopy performance using a 3-arm randomized controlled design. The tested warm-up methods are simple, universally available, and easily applicable in daily practice. The study was conducted by a team of VR simulation experts using a validated simulator (LAP Mentor). ${ }^{19,20}$ A specific strength of the study is data analysis and reporting. Simulators return multiple outcomes on different scales. Thus, large-scale

TABLE 3. Difference in Average Simulated Laparoscopy Performance Subscores for Participants in the Hands-on and iPad Group, Both Relative to the Control Group

\begin{tabular}{|c|c|c|}
\hline $\begin{array}{l}\text { Difference in Subscores (Simultaneous }{ }^{*} 95 \% \mathrm{Cl} \text { ), } \\
\text { Relative to the Control Group }(n=32)\end{array}$ & Hands-on $(n=31)$ & $\operatorname{iPad}(n=31)$ \\
\hline $\begin{array}{l}\text { Task } 1 \\
\text { Accuracy } \\
\text { Time } \\
\text { Path length camera }\end{array}$ & $\begin{array}{r}-0.2(-8.8 \text { to } 8.4) \\
3.7(-4.9 \text { to } 12.2) \\
-0.2(-8.7 \text { to } 8.4)\end{array}$ & $\begin{array}{r}-2.1(-10.7 \text { to } 6.4) \\
3.5(-5.0 \text { to } 12.1) \\
-2.2(-10.8 \text { to } 6.4)\end{array}$ \\
\hline $\begin{array}{l}\text { Tasks } 3+6 \\
\text { Accuracy } \\
\text { Time } \\
\text { Path length instruments }\end{array}$ & $\begin{array}{r}-0.0(-8.6 \text { to } 8.5) \\
4.5(-4.0 \text { to } 13.0) \\
5.2(-3.2 \text { to } 13.6)\end{array}$ & $\begin{array}{r}-1.9(-10.5 \text { to } 6.7) \\
0.6(-7.9 \text { to } 9.1) \\
-2.2(-10.6 \text { to } 6.2)\end{array}$ \\
\hline
\end{tabular}

*Multiple comparison adjustment of the confidence limits for the difference in average subscores of simulated laparoscopy performance. ${ }^{16}$ 


\begin{tabular}{|c|c|c|}
\hline & Estimate $(95 \% \mathrm{Cl})$ & p Value \\
\hline $\begin{array}{l}\text { Accuracy, task } 1 \\
\text { Hands-on } \\
\text { iPad }^{\star} \\
\text { Experience in table soccer } \\
\text { Experience in video games }\end{array}$ & $\begin{array}{r}0.9(-6.7 \text { to } 8.5) \\
-1.6(-9.1 \text { to } 5.9) \\
5.5(-3.4 \text { to } 14.5) \\
2.6(-5.4 \text { to } 10.6)\end{array}$ & $\begin{array}{l}0.814 \\
0.679 \\
0.223 \\
0.522\end{array}$ \\
\hline $\begin{array}{l}\text { Time, task } 1 \\
\text { Hands-on } \\
\text { iPad } \\
\text { Experience in table soccer } \\
\text { Experience in video games } \\
\text { Path length camera, task } 1\end{array}$ & $\begin{array}{r}4.3(-3.4 \text { to } 11.9) \\
3.8(-3.7 \text { to } 11.4) \\
-1.3(-10.3 \text { to } 7.6) \\
5.6(-2.4 \text { to } 13.6)\end{array}$ & $\begin{array}{l}0.269 \\
0.314 \\
0.767 \\
0.169\end{array}$ \\
\hline $\begin{array}{l}\text { Hands-on } \\
\text { iPad } \\
\text { Experience in table soccer } \\
\text { Experience in video games }\end{array}$ & $\begin{aligned} 0.2(-7.5 \text { to } 7.9) \\
-2.0(-9.7 \text { to } 5.6) \\
2.5(-6.6 \text { to } 11.6) \\
0.0(-8.1 \text { to } 8.2)\end{aligned}$ & $\begin{array}{l}0.962 \\
0.603 \\
0.587 \\
0.991\end{array}$ \\
\hline $\begin{array}{l}\text { Accuracy, tasks } 3+6 \\
\text { Hands-on } \\
\text { iPad }^{*} \\
\text { Experience in table soccer } \\
\text { Experience in video games }\end{array}$ & $\begin{aligned} & 1.1(-6.5 \text { to } 8.7) \\
&-1.3(-8.8 \text { to } 6.2) \\
& 5.1(-3.8 \text { to } 14.1) \\
& 3.3(-4.7 \text { to } 11.2)\end{aligned}$ & $\begin{array}{l}0.771 \\
0.731 \\
0.255 \\
0.418\end{array}$ \\
\hline $\begin{array}{l}\text { Time, tasks } 3+6 \\
\text { Hands-on } \\
\text { iPad } \\
\text { Experience in table soccer } \\
\text { Experience in video games } \\
\text { Path length instruments, tasks } 3+6\end{array}$ & $\begin{array}{l}6.0(-1.4 \text { to } 13.3) \\
1.3(-6.0 \text { to } 8.7) \\
7.8(-1.0 \text { to } 16.5) \\
3.0(-4.8 \text { to } 10.7)\end{array}$ & $\begin{array}{l}0.112 \\
0.716 \\
0.080 \\
0.452\end{array}$ \\
\hline $\begin{array}{l}\text { Hands-on } \\
\text { iPad } \\
\text { Experience in table soccer } \\
\text { Experience in video games }\end{array}$ & $\begin{array}{r}6.0(-1.5 \text { to } 13.5) \\
-1.8(-9.2 \text { to } 5.6) \\
6.6(-2.2 \text { to } 15.4) \\
-0.7(-8.6 \text { to } 7.2)\end{array}$ & $\begin{array}{l}0.116 \\
0.636 \\
0.141 \\
0.862\end{array}$ \\
\hline
\end{tabular}

* Relative to the control group.

multiple testing should be avoided and the risk of selective outcome reporting bias minimized. We therefore calculated comprehensive standardized scores, allowing calculating an overall performance for several tasks within the 3 dimensions (accuracy, time, and path length). Simulator tasks were carefully selected, imposing participants to demonstrate all 3 required dimensions of VR performance. In the age of time efficiency, pressure in surgeon's daily work, and working time restrictions, warm-up must be as long as necessary but as short as possible. Therefore, we selected 5 minutes as an appropriate time period for the warm-up, as shown to be effective in other studies. ${ }^{10}$

That we used laypersons, rather than surgeons, may be considered the main limitation of our study. However, there are several reasons that led us to choose laypersons as the population of interest for this study. Firstly, this trial is very insightful for the design of a subsequent trial in surgeons; it informs trial design of the follow-up study concerning several aspects: (1) choice of intervention (method and duration of warm-up), (2) targeted surgeon population, and (3) targeted sample size. We learnt the following from this study: (1) we should consider choosing a warm-up more closely related to the subsequent task and increase the duration of warm-up, (2) it might be important to include surgeons of different levels of experience, as there is some uncertainty as to whether novice surgeons benefit from this type of warm-up, and (3) more about the expected performance score and variance in surgically inexperienced testees, which is important for sample size calculation. Secondly, this study is not only important for the design of a subsequent study but also merits to be considered as a stand-alone investigation, as we do actually believe that surgical novices represent a population comparable to laypersons. This is supported within this trial by the fact that the exercises chosen do not require any anatomical or surgical knowledge. Therefore, we may conclude from this study that surgical novices potentially benefit more from a warm-up more closely related to the future task. This is in turn important in the educational setting. Thirdly, for pragmatic reasons in feasibility, we felt it to be easier to start with laypersons, as it may be a challenge to recruit so many surgeons, especially if we additionally want to investigate any subgroup effect depending on the level of experience.

\section{Relation to Other Studies}

Our findings support a recently published trial where nonsurgical and surgical warm-up strategies did not show a significant effect on performance. ${ }^{2}$ Mucksavage et al. ${ }^{8}$ 
demonstrated an operation time reduction from 388 (SD = 65) to 334 minutes $(S D=65)$ for radical nephrectomies following a 20-minute suturing task warm-up, whereas all other clinically important outcomes were not affected by warm-up in this study. Conversely, other studies found a positive effect of warm-up on surgical performance. For the purpose of surgical warm-up, VR simulators ${ }^{4-7}$ and pelvitrainers $^{2,3,8,9}$ were most frequently used. Calatayud et al. ${ }^{5}$ found a better surgical performance following a 15-minute warm-up on a VR simulator directly before laparoscopic cholecystectomy. Do et al. ${ }^{3}$ found significant improvement after warm-up using a pelvitrainer, but the effect of the pure learning effect was not considered. Kahol et al. ${ }^{4}$ found significant improvement during a VR simulator electrocautery task following a 20-minute warm-up (virtual ring transfer task), independently of the level of experience. Lee at al. ${ }^{7}$ demonstrated that warm-up with a VR simulator or with pelvitrainer improved performance in renal surgery. In another study, ${ }^{6}$ warm-up improved psychomotor skills, but the results are limited owing to a potential carry-over learning effect. Lendvay et al. ${ }^{10}$ showed that even a short VR laparoscopy warm-up can improve outcomes. In a recent study, Chen et al. ${ }^{9}$ showed improvement after warm-up in gynecological surgery, independently of the difficulty of surgery and experience of residents. Komesu et al. ${ }^{11}$ found that mental imagery of surgical steps before surgery improves performance.

Nonsurgical warm-up was evaluated in some studies too. Bokhari et al. ${ }^{12}$ showed that playing video games as warmup led to fewer errors and superior movement proficiency in a VR simulator electrocautery task. Plerhoples et al. ${ }^{13}$ showed that playing a mobile device (balance game) led to fewer errors in VR simulator basic tasks. Rosser et al. ${ }^{14}$ demonstrated that playing video games reduced the time and increased the overall score in a pelvitrainer task.

\section{Mechanisms Explaining the Findings}

First, although a positive effect of nonsurgical warm-up strategies has been shown in a few studies, ${ }^{12-14}$ the skills practiced during such a warm-up may not be comparable to those required in the real operating room. Our hands-on warm-up focused on musculoskeletal warming, rather than spatial priming. This approach was chosen based on the positive effect of warm-up on physical performance, as suggested in a meta-analysis. ${ }^{21}$ Grip function and proprioception can be significantly improved by warm-up. ${ }^{22}$ However, the effect of a warm-up with table soccer may be limited to a pure musculoskeletal preconditioning being too dissimilar and too rough compared with the subsequent VR laparoscopic tasks. The cognitive warm-up relied on the transfer of a $3 \mathrm{D}$ environment to a $2 \mathrm{D}$ environment and spatial skills and thus tackles one of the most important challenges in laparoscopic surgery, the loss of the third dimension. ${ }^{23,24}$ However, it may be assumed that participants can compensate for the loss of the third dimension. Thus, the applied tablet 3D puzzle may fail its purpose. Secondly, the short duration of the warm-up in our study may explain the lack of effect on performance. Spatial skills are innate abilities, ${ }^{25}$ and therefore a training effect might take longer than 5 minutes. In other studies evaluating cognitive warmup using mobile devices or video games ${ }^{13,14}$ resulting in improved VR performance, warm-up was conducted for at least 10 minutes, suggesting that warm-up time may play an important role. Third, some of the studies showing a positive effect of warm-up were not randomized, investigated a surgical warm-up, or evaluated real surgery performance s-9 $^{5}$ and are thus not directly comparable to our study. Last, although we conducted a formal sample size calculation, our assumptions were derived from previous investigations in similar but not identical settings and populations.

\section{Implications for Further Research and Daily Practice}

It remains unclear whether a longer warm-up or a warm-up more similar in setting and content to the final task results in an improvement of surgical performance. For this reason, based on a formal sample size calculation, we plan to conduct a follow-up RCT including surgeons stratified by their level of experience. This trial will comprise longer warm-up modalities closer related to the subsequent task and record patient-relevant outcomes, with the ultimate goal to enhance patient safety.

\section{Conclusions}

The effect of different warm-up strategies on surgical performance remains controversial. Although we were unable to demonstrate an effect of 2 nonsurgical warm-up strategies on VR simulator performance, a relevant effect of warm-up on simulated and operating room performance has been claimed in most previous studies, ${ }^{3-14}$ many of which however present methodological drawbacks. As further research, we currently design a follow-up trial with surgeons as study participants using the findings from this study to inform trial design.

\section{REFERENCES}

1. Wetter PA, Rovira IK. "Do no harm"-ORReady initiative aims to improve safety and outcome for 6 million patients. J Soc Laparoendosc Surg. 2011;15(2):131-132.

2. Weston MK, Stephens JH, Schafer A, Hewett PJ. Warm-up before laparoscopic surgery is not essential. ANZ J Surg. 2014;84(3):143-147.

3. Do AT, Cabbad MF, Kerr A, Serur E, Robertazzi RR, Stankovic MR. A warm-up laparoscopic exercise improves the subsequent laparoscopic performance of 
ob-gyn residents: a low-cost laparoscopic trainer. J Soc Laparoendosc Surg. 2006;10(3):297-301.

4. Kahol K, Satava RM, Ferrara J, Smith ML. Effect of short-term pretrial practice on surgical proficiency in simulated environments: a randomized trial of the "preoperative warm-up" effect. J Am Coll Surg. 2009;208(2):255-268.

5. Calatayud D, Arora S, Aggarwal R, et al. Warm-up in a virtual reality environment improves performance in the operating room. Ann Surg. 2010;251(6):1181-1185.

6. Moldovanu R, Târcoveanu E, Dimofte G, Lupaşcu C, Bradea C. Preoperative warm-up using a virtual reality simulator. J Soc Laparoendosc Surg. 2011;15(4):533-538.

7. Lee JY, Mucksavage P, Kerbl DC, et al. Laparoscopic warm-up exercises improve performance of senior-level trainees during laparoscopic renal surgery. J Endourol. 2012;26(5):545-550.

8. Mucksavage P, Lee J, Kerbl DC, Clayman RV, McDougall EM. Preoperative warming up exercises improve laparoscopic operative times in an experienced laparoscopic surgeon. J Endourol. 2012;26(7):765-768.

9. Chen CCG, Green IC, Colbert-Getz JM, et al. Warmup on a simulator improves residents' performance in laparoscopic surgery: a randomized trial. Int Urogynecol J. 2013;24(10):1615-1622.

10. Lendvay TS, Brand TC, White L, et al. Virtual reality robotic surgery warm-up improves task performance in a dry laboratory environment: a prospective randomized controlled study. J Am Coll Surg. 2013;216(6):1181-1192.

11. Komesu Y, Urwitz-Lane R, Ozel B, et al. Does mental imagery prior to cystoscopy make a difference? A randomized controlled trial Am J Obstet Gynecol. 2009;201(2):218.e1-218.e9.

12. Bokhari $R$, Bollman-McGregor $J$, Kahoi $K$, Smith M, Feinstein A, Ferrara J. Design, development, and validation of a take-home simulator for fundamental laparoscopic skills: using Nintendo Wii for surgical training. Am Surg. 2010;76(6):583-586.

13. Plerhoples TA, Zak Y, Hernandez-Boussard T, Lau J. Another use of the mobile device: warm-up for laparoscopic surgery. J Surg Res. 2011;170(2):185-188.

14. Rosser JC, Gentile DA, Hanigan K, Danner OK. The effect of video game "warm-up" on performance of laparoscopic surgery tasks. J Soc Laparoendosc Surg. 2012;16(1):3-9.

15. Streiner DL, Norman GR. Health Measurement Scales: A Practical Guide to Their Development and Use. Oxford: Oxford Univ. Press; 2008.

16. Dunnett CW. A multiple comparison procedure for comparing several treatments with a control. J Am Stat Assoc. 1955;50(272):1096-1121.

17. Sarkar D. Lattice: Multivariate Data Visualization With R. New York: Springer New York; 2008.

18. Rosenthal R, Geuss $S$, Dell-Kuster $S$, Schäfer J, Hahnloser D, Demartines N. Video gaming in children improves performance on a virtual reality trainer but does not yet make a laparoscopic surgeon. Surg Innov. 2011;18(2):160-170.

19. Ayodeji ID, Schijven M, Jakimowicz J, Greve JW. Face validation of the Simbionix LAP Mentor virtual reality training module and its applicability in the surgical curriculum. Surg Endosc. 2007;21(9):1641-1649.

20. Zhang A, Hünerbein M, Dai $Y$, Schlag PM, Beller S. Construct validity testing of a laparoscopic surgery simulator (Lap Mentor): evaluation of surgical skill with a virtual laparoscopic training simulator. Surg Endosc. 2008;22(6):1440-1444.

21. Fradkin AJ, Zazryn TR, Smoliga JM. Effects of warming-up on physical performance: a systematic review with meta-analysis. J Strength Cond Res. 2010;24(1):140-148.

22. Magalhães $T$, Ribeiro $F$, Pinheiro $A$, Oliveira $J$. Warming-up before sporting activity improves knee position sense. Phys Ther Sport. 2010;11(3):86-90.

23. Gallagher AG, Ritter $E M$, Lederman $A B$, McClusky DA, Smith CD. Video-assisted surgery represents more than a loss of three-dimensional vision. Am J Surg. 2005;189(1):76-80.

24. Hanna GB, Cuschieri A. Influence of two-dimensional and three-dimensional imaging on endoscopic bowel suturing. World J Surg. 2000;24(4):444-449.

25. Rosenthal R, Hamel C, Oertli D, Demartines N, Gantert WA. Performance on a virtual reality angled laparoscope task correlates with spatial ability of trainees. Indian J Surg. 2010;72(4):327-330. 